\title{
Impact of 5-Ply Toilet Paper Configuration on Its Mechanical and Absorption Properties
}

\author{
Joana Costa Vieira, ${ }^{\mathrm{a}, *}$ António de Oliveira Mendes, ${ }^{\mathrm{a}}$ Ana Margarida Carta, \\ Paulo Torrão Fiadeiro, ${ }^{\mathrm{a}}$ and Ana Paula Costa ${ }^{\mathrm{a}}$ \\ Several physical and mechanical properties can characterize tissue \\ papers. In particular, low grammage but high values of bulk, flexibility, \\ liquid absorption capacity, and softness are common properties for tissue \\ papers. These properties must be adapted to meet the requirements of \\ the final consumer, which can vary greatly in different countries. This work \\ resulted from a study regarding the impact of two different stacking \\ sequences of 5-ply toilet paper with configurations 1 and 2 (deco:micro \\ embossing of 3:2 and 2:3 plies, respectively), which had the same base \\ tissue papers in each mother reel, on their mechanical behavior and \\ absorption capacity. The stacking sequence of the plies influenced the \\ properties of the finished toilet paper. For configurations 1 and 2, after the \\ embossing process, bulk increases of $46 \%$ and $40 \%$, respectively, and \\ water absorption capacity increases of $2 \%$ and $17 \%$, respectively, were \\ registered. In this case, the bulk increase was not the key property that \\ influenced the water absorption capacity. Regarding mechanical \\ properties, both configurations showed a higher negative impact caused \\ by the deco embossing. For commercial purposes and to adhere to the \\ final consumers' preferences for toilet paper, configuration 1 was more \\ suitable for mechanical strength, and configuration 2 was more suitable \\ for absorption capacity.
}

Keywords: Tissue toilet paper; Paper stacking sequence; Paper morphology; Liquid absorption capacity; Mechanical properties

Contact information: a: Universidade da Beira Interior, Fiber Materials and Environmental Technologies (FibEnTech-UBI), Rua Marquês de Ávila e Bolama, 6201-001, Covilhã, Portugal; b: RAIZ - Instituto de Investigação da Floresta e Papel, Quinta de S. Francisco, Apartado 15, 3801-501, Eixo, Portugal;

*Corresponding author: joana.costa.vieira@ubi.pt

\section{INTRODUCTION}

Tissue paper is produced from the deposition of a mixture of short cellulosic fibers with a lower percentage of long cellulosic fibers, and sometimes starch is added to increase dry strength. The mixture of ingredients is present in an aqueous suspension at consistency of approximately $0.8 \%$ as a moving wet-web of fibers on a forming fabric. Through a filtration process $95 \%$ of the water is then removed. After the forming zone, the base paper is carried to the pressing zone. The purpose of pressing is to remove the water and consolidate the paper structure. This promotes contact between fibers in the presence of water as a binder to establish inter-fiber connections. The drying section, which is the final step, removes the remaining water from the tissue structure. In this part of the paper machine, water is evaporated by heat transfer and consequent condensation of steam within a large steel dryer cylinder called the Yankee dryer. With the introduction of TAD (Through-Air Drying) technology in the drying section of the tissue paper machine, the manufacturers were able to produce final products with higher bulk, softness, and liquid 
absorption. This technology is more advantageous to produce premium tissue papers, but at the expense of greater energy consumption (De Assis et al. 2018; Wang et al. 2019). The tissue paper is detached from the surface of this cylinder with the aid of a creping blade, as schematically shown in Fig. 1, which ultimately produces the creped base paper. Finally, the produced base paper is wound up to form the reel. This paper reel will then generate multiple mother reels to feed the converting machine to produce the finished product (Ramasubramanian et al. 2011; Das 2019).

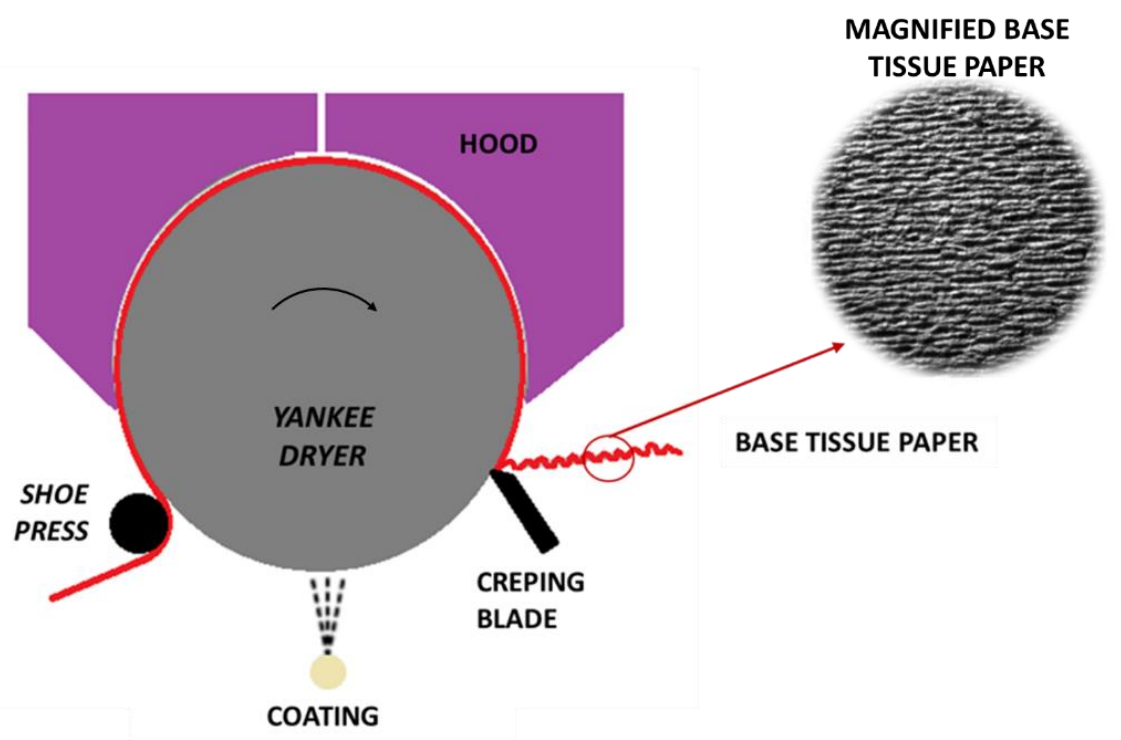

Fig. 1. Scheme of the tissue paper detachment from the surface of Yankee cylinder (creping process)

Converting machines include several processes, such as unwinding, embossing, lamination, printing, punching, packaging, and palletization, to produce multilayer tissue papers (Spina and Cavalcante 2018; Vieira et al. 2020). Embossing is a method of papercompressive formation in the converting lines. Deco embossing is performed in the top surface of toilet paper product having one or more plies. Its main purpose is related to decoration and marketing. Micro embossing is engraved in the bottom surface of the toilet paper, and its main purpose will be to give bulk to the paper. Both surfaces will be assembled using the embossing details to glue them together. Embossing is used to modify the properties of the finished product, such as water absorption capacity, softness, and bulk. Despite improving some properties, this process deteriorates others, such as tensile strength (Spina and Cavalcante 2018; Vieira et al. 2020).

The properties of tissue papers are generally influenced by the requirements of the consumer. Therefore, the production process must be adapted to meet these requirements. Such properties differ depending on destination country, which requires that they must be evaluated with consideration to each market (De Assis et al. 2018). The physicalmechanical properties of the base tissue paper are usually evaluated in terms of grammage, thickness, bulk, and tensile strength in the machine direction (MD) and cross direction (CD). These values change according to the manufacturing machine and suppliers (Spina and Cavalcante 2018).

Bulk, which is the inverse of its apparent density, is an important property of tissue papers that defines the volume occupied by a given grammage. Strategies to improve the 
bulk of tissue paper include lowering the pressure in the wet pressing zone and/or using a low refining level in the fibers, changing the creping process itself, using a composition rich in fibers with high coarseness $(\mathrm{mg} / 100 \mathrm{~m})$, keeping low flexibility of fibers, or orienting paper in the MD (Kullander 2012; De Assis et al. 2018).

The most relevant and differentiating physical-mechanical properties of the finished toilet paper products are bulk, liquid absorption, mechanical strength, and softness. Understanding how they are related, and how changing one property affects the others remains a challenge.

The liquid absorption of toilet paper products is usually divided into absorption capacity and absorption time. Absorption capacity reflects the maximum amount of water that it can absorb and is the ratio between the mass of absorbed water:mass of fibers $(\mathrm{g}: \mathrm{g})$, whereas the absorption time measures how quickly the product absorbs that amount of water (s) (Kullander 2012). These properties are influenced by the type of fibers, content of fines and inorganic additives, refining, fibrous network structure, pressing, creping, number of plies, grammage, bulk, and porosity. Common toilet papers present a range of water absorption between 6 to $13 \mathrm{~g}$ of water per $\mathrm{g}$ of fiber, while premium/ultra toilet paper products can absorb up to $18 \mathrm{~g}$ of water per $\mathrm{g}$ of fiber (Kullander 2012; Hubbe et al. 2013; De Assis et al. 2018; Wang et al. 2019). Absorption measurements reflect the ability of a toilet paper to hold a liquid. Hydroxyl groups on the cellulose surface promote hydrogen bonds with water, which directly affects water absorption (Bracken 2014). In European and International trades, both water absorption capacity and water absorption time are important requirements used to compare different tissue papers (Tutuş et al. 2016).

The papermaking process modifies the physical-mechanical properties of tissue papers. These properties are influenced by the intrinsic strength of the fibers and the interfiber bonds. Long fibers and various additives (carboxymethylcellulose and starch) are employed to increase dry tensile strength (Hollmark 1984; De Assis et al. 2018). The refining of the fibrous suspension, due to internal and external fibrillation, also increases the tensile strength as the fibers become more flexible and accommodated, which improves their fiber-fiber bonding abilities. However, the fibers can be damaged due to the refining process (Kullander 2012; Boudreau 2013). The strength of the tissue paper is reduced by the creping process and further reduced in the converting lines by the embossing process, as the inter-fiber bonds are broken (Kullander 2012; Boudreau 2013). Creping increases maximum deformation and toughness and decreases strength and stiffness, in both the MD and CD, with a particularly major impact on the MD (Das 2019). However, the elongation in the $\mathrm{CD}$ is important so that the operability in the converting occurs successfully, as in the case of embossing. The Young's modulus of the dried crepe tissue paper influences the softness of the bulk (compressibility). Therefore, a better understanding of the main mechanisms that influence the tissue paper response to tensile loading (characterized by tensile index and related to strength), Young's modulus, and maximum strain, is necessary to successfully design a tissue paper geared to consumer needs that can be produced at an efficient speed (Das 2019).

This work presents the results of a study on the impact of two different stacking sequences of 5-ply toilet paper with the same base tissue papers on their mechanical behavior and absorption capacity. Adjusting and control of the plies stacking sequence might represent an alternative to produce toilet tissue papers, because that will have a direct impact on the final properties of them. Toilet papers with two different configurations, which were produced by two different mother reels forming two different stacking 
sequences, were compared in terms of water absorption (before and after the embossing process) and tensile strength.

\section{EXPERIMENTAL}

\section{Materials}

For this study 5-ply commercial toilet papers, which were assembled by two different mother reels (one mother reel with 2-ply and the other with 3-ply), forming two different stacking sequences (configurations 1 and 2), were used. In configuration 1, the 3ply mother reel was on top (deco embossing), and the 2-ply mother reel was on the bottom (micro embossing). In configuration 2, the inverse of configuration 1 was applied, the 2ply mother reel was on top (deco embossing), and the 3-ply mother reel was on the bottom (micro embossing). The configurations are presented in Fig. 2. The two commercial toilet papers and the corresponding mother reels were collected at a Portuguese factory line that were produced using a mixture of $85 \%$ hardwood eucalyptus and $15 \%$ softwood pine and spruce European virgin bleached kraft pulps. The tissue base paper was produced in a DCT (dry crepe technology) paper machine. All the tissue papers samples were conditioned according to the standard ISO 187 (1990).

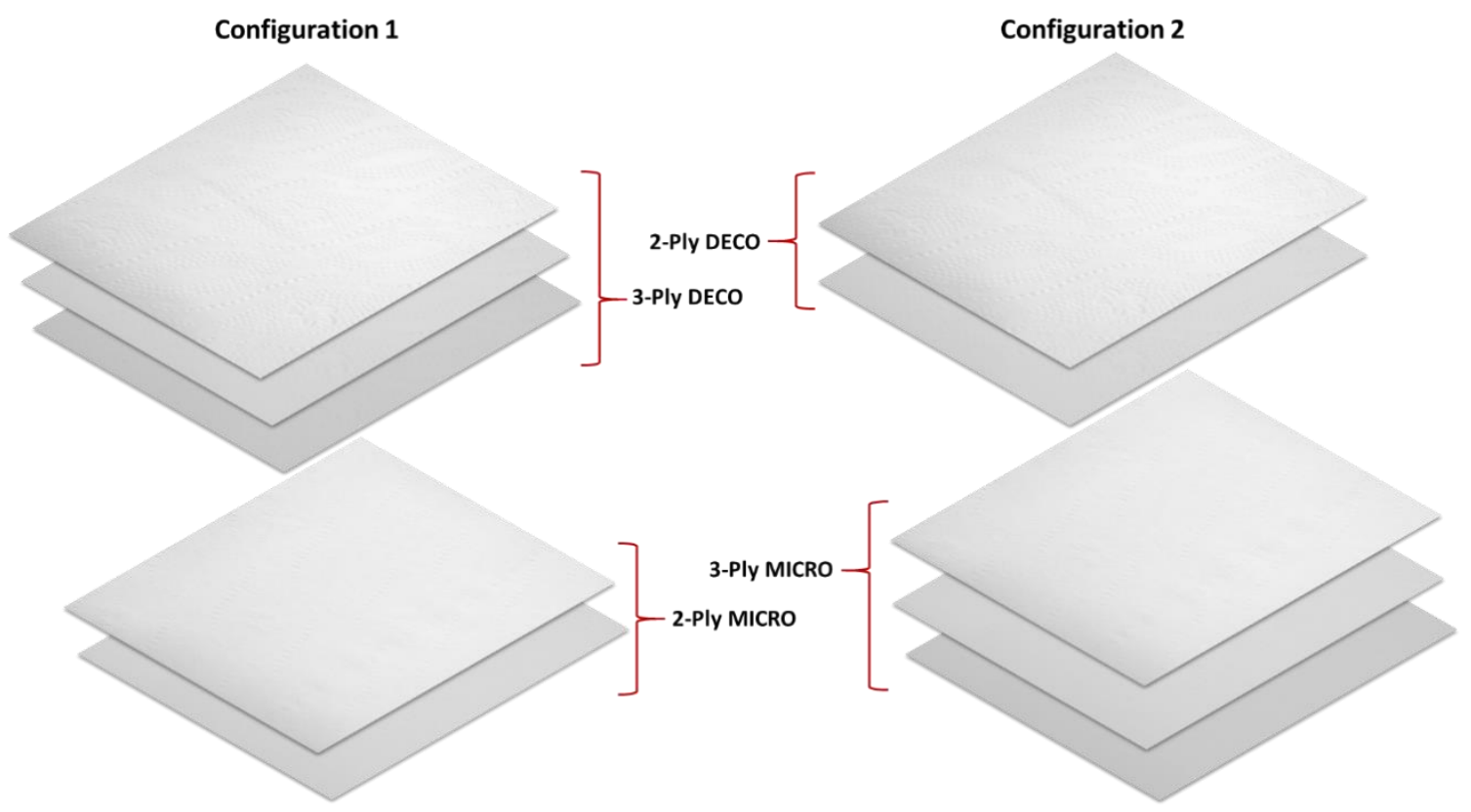

Fig. 2. Stacking sequences of the two configurations of the 5-ply toilet papers

\section{Methods}

First, the morphology of both the finished toilet papers and the mother reels that produced them were determined. These tests were conducted using the MORFI ${ }^{\circledR}$ Fiber and Shive Analyser (Techpap SAS, Grenoble, France), and the values for fiber length and width, curl, kink fibers, coarseness, long and short fiber distribution, broken ends, and fines percentage were obtained. Then, the grammage, was determined and expressed in $\mathrm{g} / \mathrm{m}^{2}$, which is defined as the mass per unit of paper area. A PB303 Delta Range analytical balance (Mettler Toledo, Columbus, OH, USA) was used to weigh the paper samples of a known area in accordance with ISO 12625-6 (2005). The thickness was determined 
according to ISO 12625-3 (2014) with a FRANK-TPI Micrometer (Birkenau, Germany) for tissue paper. The measure of the assembled mother reels (without embossing) were done using the stacking sequences. Finally, the bulk, which is the inverse of density, was determined according to ISO 12625-3 (2014) with known thickness and grammage.

Absorption time and absorption capacity were then measured using a tissue absorption tester (FRANK-PTI GMBH, Birkenau, Germany) according to ISO 12625-8 (2010) via the immersion method. Toilet paper samples were cut according to ISO 126258 (2010), and the mother reel samples were cut along MD width according to the standard and along length according to the service length of the toilet paper from which they were originated (Vieira et al. 2020). The assembled mother reel samples (without embossing) were prepared using the stacking sequences until obtain $5 \mathrm{~g}$ of total base tissue paper mass.

Tensile tests were performed on a VantageNX universal testing machine (ThwingAlbert Instrument Company, West Berlin, NJ, USA) in accordance with ISO 12625-4 (2005). In a tensile test, tensile strength is the maximum tensile force per unit width that a test piece can withstand before breaking. These tests were performed on both finished toilet papers and mother reels that produced them.

The porosity for all the base mother reels and toilet papers samples was determined using a Micromeritics AccuPyc II 1340 helium pycnometer (Micromeritics, Norcross, GA, USA).

\section{RESULTS AND DISCUSSION}

Table 1 presents the morphological characteristics of the 2-ply mother reel, the 3ply mother reel, and the 5-ply toilet paper samples. Figure 3 shows the percentages of the fibrous distribution in relation to the length weighted in length and in relation to the width of the fibers.

Table 1. Mean Values and Standard Deviations of the Morphological Results Obtained for the 2-ply Mother Reel, 3-ply Mother Reel, and 5-ply Toilet Paper

\begin{tabular}{|c|c|c|c|c|c|c|}
\hline \multirow{2}{*}{ Morphology } & \multicolumn{2}{|c|}{$\begin{array}{c}\text { 2-ply } \\
\text { Mother Reel }\end{array}$} & \multicolumn{2}{c|}{$\begin{array}{c}\text { 3-ply } \\
\text { Mother Reel }\end{array}$} & \multicolumn{2}{c|}{$\begin{array}{c}\text { 5-ply } \\
\text { Toilet Paper }\end{array}$} \\
\cline { 2 - 7 } & $\overline{\mathbf{X}}$ & $\boldsymbol{\sigma}$ & $\overline{\mathbf{X}}$ & $\boldsymbol{\sigma}$ & $\overline{\mathbf{X}}$ & $\sigma$ \\
\hline Fibers (million/g) & 17.6 & \pm 0.2 & 19.5 & \pm 0.3 & 18.3 & \pm 0.3 \\
\hline Length Weighted in Length $(\mathrm{mm})$ & 0.817 & \pm 0.006 & 0.736 & \pm 0.004 & 0.768 & \pm 0.004 \\
\hline Width $(\mu \mathrm{m})$ & 19.5 & \pm 0.1 & 19.6 & \pm 0.1 & 19.6 & \pm 0.1 \\
\hline Coarseness $(\mathrm{mg} / 100 \mathrm{~m})$ & 8.52 & \pm 0.12 & 8.53 & \pm 0.13 & 8.73 & \pm 0.11 \\
\hline Kink Fibers (\%) & 46.7 & \pm 0.5 & 49.8 & \pm 0.1 & 48.3 & \pm 0.1 \\
\hline Curl (\%) & 9.9 & \pm 0.0 & 11.1 & \pm 0.0 & 10.6 & \pm 0.0 \\
\hline Broken Ends (\%) & 23.2 & \pm 0.3 & 24.6 & \pm 0.5 & 24.8 & \pm 0.7 \\
\hline Fines (\% Area) & 14.2 & \pm 0.3 & 16.1 & \pm 0.3 & 15.9 & \pm 0.6 \\
\hline
\end{tabular}

Analysis of the morphological properties presented in Table 1 verified that the fibrous composition of the 5-ply finished toilet paper had an average value similar to the values of the mother reels from which they were produced. These results showed a fiber composition that consisted mainly of short fiber (hardwood), which was in line with reference literature (Niskanen et al. 1998), to obtain a better formation and softness of the tissue paper base sheet. Because the two finished toilet paper configurations were produced 
from the same base paper (only the mother reels were changed in the converting machine), the morphological composition was not an influencing factor on the results obtained in the remaining tests. Figure 3 confirms the existence of a major quantity of short fiber. The distributions presented in Figs. 3a and 3b show that there was a slightly higher percentage of long fiber (softwood) in terms of length $(>2.000 \mathrm{~mm})$ and width $(>30 \mu \mathrm{m})$ for the 2-ply mother reel. As expected, for both mother reels, the small percentage of long fiber was used to increase the strength properties of the papers and ensure process runnability.
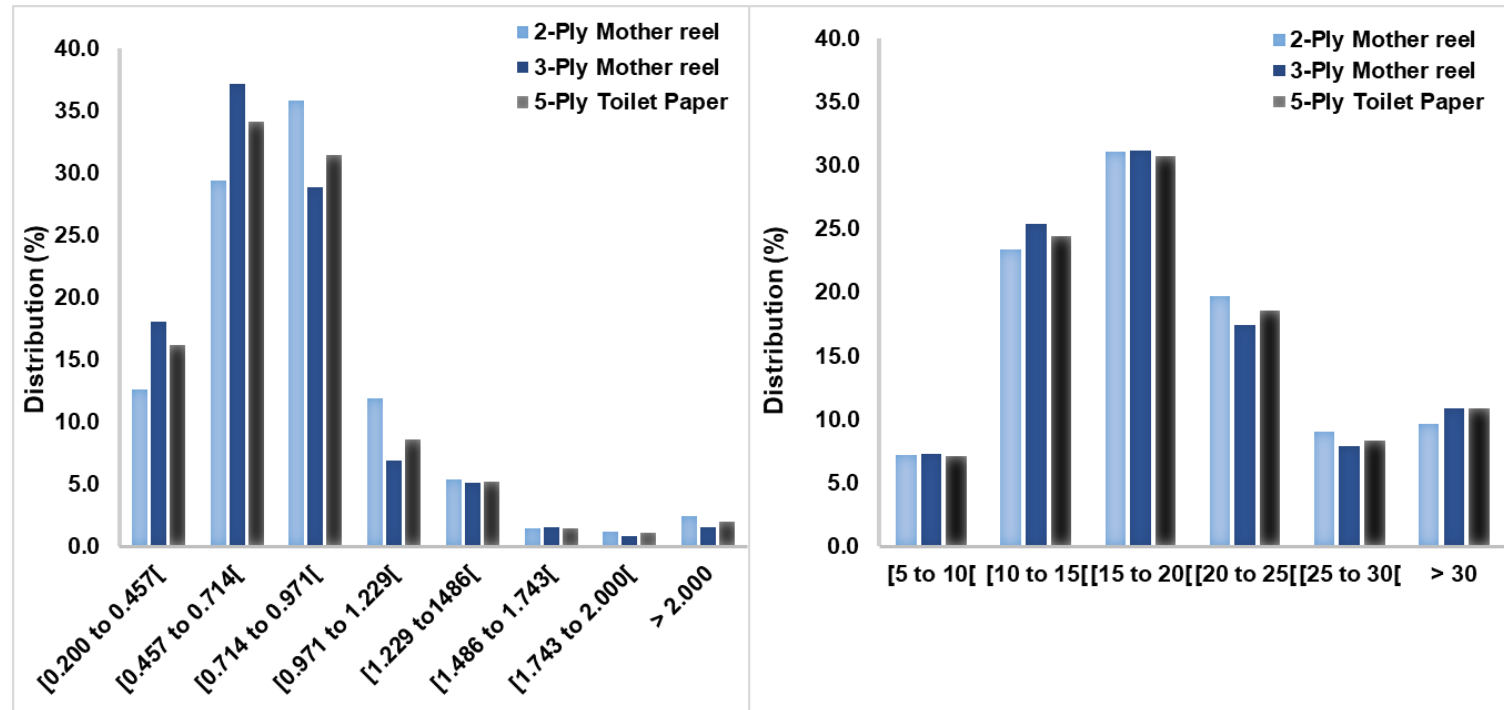

a) Length-weighted in length $(\mathrm{mm})$

b)

Width $(\mu \mathrm{m})$

Fig. 3. Percentages of fibrous distribution for the 2-ply and 3-ply mother reels and the 5-ply toilet paper in relation to the: a) length weighted in length and b) width

Table 2 shows the tissue paper structural properties, namely grammage, thickness, and bulk for the studied samples.

Table 2. Structural Properties of Grammage, Thickness, and Bulk of the Mother Reels (2-Ply + 3-Ply) and the 5-ply Toilet Papers in Configurations 1 and 2

\begin{tabular}{|c|c|c|c|}
\cline { 2 - 4 } \multicolumn{1}{c|}{} & $\begin{array}{c}\text { Mother Reels } \\
\text { (2-ply + 3-ply) }\end{array}$ & $\begin{array}{c}\text { Toilet Paper } \\
\text { Configuration 1 }\end{array}$ & $\begin{array}{c}\text { Toilet Paper } \\
\text { Configuration 2 }\end{array}$ \\
\hline Grammage $\left(\mathrm{g} / \mathrm{m}^{2}\right)$ & 78.9 & 76.0 & 76.4 \\
\hline Thickness $(\mu \mathrm{m})$ & 514 & 725 & 695 \\
\hline Bulk $\left(\mathrm{cm}^{3} / \mathrm{g}\right)$ & 6.5 & 9.5 & 9.1 \\
\hline
\end{tabular}

Table 2 shows that the grammage of the finished toilet papers decreased slightly relative to the mother reels. Due to the converting process thickness and bulk increased with these operations. The measure of the thickness of the assembled mother reels (2-ply +3 -ply or 3-ply + 2-ply) was the same because there is no contribution of the embossing process.

Table 3 summarizes the mean values and standard deviations of the results for the porosity tests of all tissue samples under study. The tabulated data shows that the porosity obtained for the different papers (mother reels and finished toilet papers) was very high. It 
also shows that the porosity with the embossing was increased, being higher in configuration 2 .

Table 3. Mean Values and Standard Deviation of the Porosity Tests of the Mother Reels (2-ply + 3-ply) and the 5-ply Toilet Papers in Configurations 1 and 2

\begin{tabular}{|l|c|c|}
\cline { 2 - 3 } \multicolumn{1}{c|}{} & \multicolumn{2}{c|}{ Porosity (\%) } \\
\cline { 2 - 3 } \multicolumn{1}{c|}{} & $\overline{\mathbf{X}}$ & $\sigma$ \\
\hline Mother Reels (2-ply + 3-ply) & 89.39 & \pm 0.01 \\
\hline Toilet Paper Configuration 1 & 90.17 & \pm 0.01 \\
\hline Toilet Paper Configuration 2 & 90.52 & \pm 0.01 \\
\hline
\end{tabular}

Table 4 summarizes the mean values and standard deviations of the results for the water absorption time and absorption capacity tests of all samples under study.

Table 4. Mean Values and Standard Deviation of the Results of the Water Absorption Time and Absorption Capacity Tests of the Mother Reels (2-ply + 3ply) and the 5-ply Toilet Papers in Configurations 1 and 2

\begin{tabular}{|l|c|c|c|c|}
\cline { 2 - 5 } \multicolumn{1}{c|}{} & \multicolumn{2}{c|}{ Water Absorption Time (s) MD } & \multicolumn{2}{c|}{ Absorption Capacity (g/g) MD } \\
\cline { 2 - 5 } \multicolumn{1}{c|}{} & $\overline{\mathbf{X}}$ & $\boldsymbol{\sigma}$ & $\overline{\mathbf{X}}$ & $\boldsymbol{\sigma}$ \\
\hline Mother Reels (2-ply + 3-ply) & 4.54 & \pm 0.23 & 8.33 & \pm 0.16 \\
\hline Toilet Paper Configuration 1 & 4.53 & \pm 0.27 & 8.49 & \pm 0.20 \\
\hline Toilet Paper Configuration 2 & 3.76 & \pm 0.44 & 9.74 & \pm 0.16 \\
\hline
\end{tabular}

Table 4 shows that the water absorption time obtained for the different papers (mother reels and finished toilet papers) was practically the same, which indicates that the porosities and fibrous structural networks were similar. The small changes in the absorption capacity are in accordance with the porosity results obtained, being higher in configuration 2 in both tests (Vieira et al. 2020).

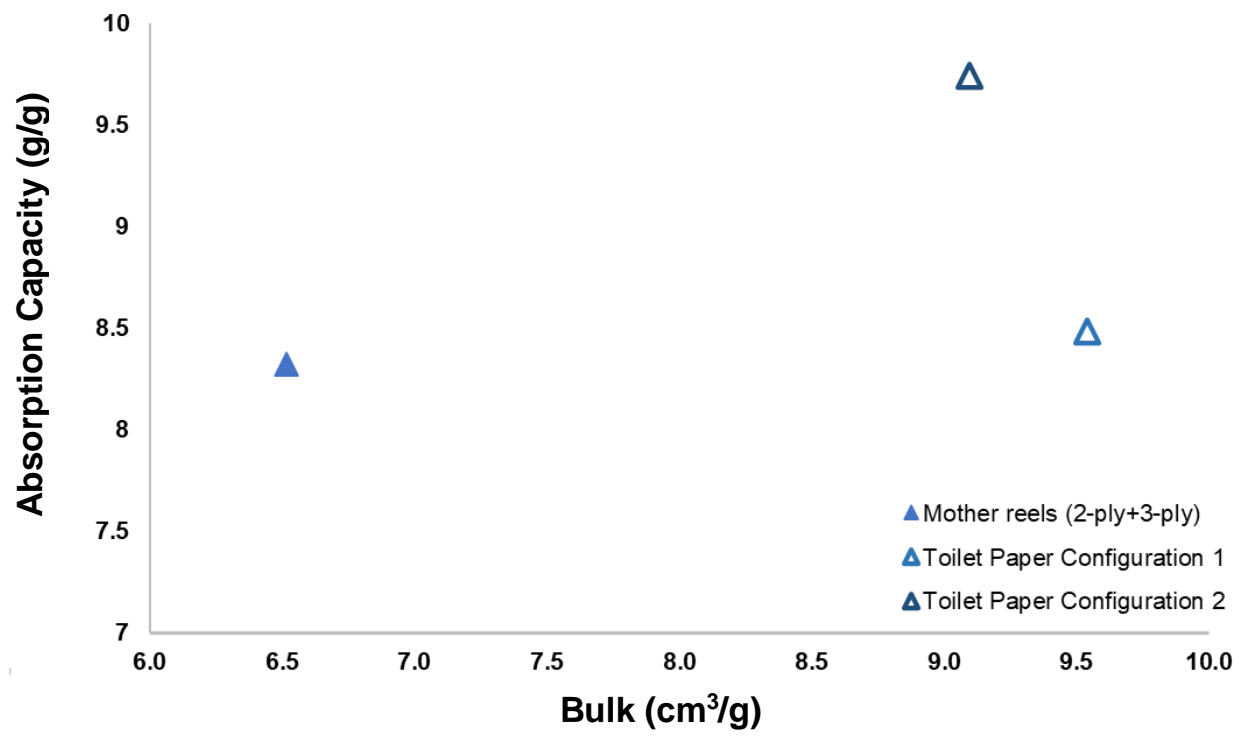

Fig. 4. Variation of water absorption capacity with bulk of the tested samples 
Figure 4 shows that the water absorption capacity increased as bulk increased. Due to the embossing process, bulk increases of $46 \%$ and $40 \%$ were observed for toilet paper configurations 1 and 2, respectively. This led to an increase in water absorption capacity of $2 \%$ and $17 \%$ for configurations 1 and 2 , respectively. The rearrangement of the mother reels (2-ply +3 -ply and 3-ply +2 -ply) in the finished paper configuration influenced the water absorption capacity and porosity. A larger number of micro-embossed sheets (configuration 2) promoted a higher water absorption capacity due to the creation of a larger number of empty spaces (high porosity) for liquid retention (Vieira et al. 2020).

Finally, Tables 5, 6, and 7 present the average results obtained for the tissue paper mechanical properties, which included tensile index, maximum strain, and Young's modulus in MD and CD.

Table 5. Tensile Test Results (Tensile Index, Maximum Strain, and Young's Modulus) of the Two Mother Reels (2-ply and 3-ply) in the MD and the CD

\begin{tabular}{|c|c|c|c|c|}
\cline { 2 - 5 } \multicolumn{1}{c|}{} & \multicolumn{2}{c|}{ 2-ply Mother Reel } & \multicolumn{2}{c|}{ 3-ply Mother Reel } \\
\cline { 2 - 5 } \multicolumn{1}{c|}{} & CD & MD & CD & MD \\
\hline Tensile Index (Nm/g) & 4.9 & 10.1 & 4.9 & 9.6 \\
\hline Maximum Strain (\%) & 4.2 & 24.2 & 4.0 & 27.5 \\
\hline Young Modulus (MPa) & 24.5 & 11.9 & 31.4 & 9.3 \\
\hline
\end{tabular}

Table 6. Tensile Test Results (Tensile Index, Maximum Strain, and Young's Modulus) for Configuration 1 of the 5-ply Toilet Paper and the Corresponding 3ply Deco Embossing Paper and 2-ply Micro Embossing Paper

\begin{tabular}{|c|c|c|c|c|c|c|}
\hline \multirow{2}{*}{ Configuration 1 } & \multicolumn{2}{|c|}{ 2-ply MICRO Paper } & \multicolumn{2}{c|}{ 3-ply DECO Paper } & \multicolumn{2}{c|}{ 5-ply Toilet Paper } \\
\cline { 2 - 7 } & CD & MD & CD & MD & CD & MD \\
\hline Tensile Index (Nm/g) & 4.6 & 8.9 & 2.2 & 6.8 & 3.6 & 7.9 \\
\hline Maximum Strain (\%) & 4.9 & 18.6 & 5.9 & 18.5 & 6.4 & 19.9 \\
\hline Young Modulus (MPa) & 11.9 & 7.7 & 3.4 & 3.2 & 7.7 & 5.1 \\
\hline
\end{tabular}

Table 7. Tensile Test Results (Tensile Index, Maximum Strain, and Young's Modulus) for Configuration 2 of the 5-ply Toilet Paper and the Corresponding 2ply Deco Embossing Paper and 3-ply Micro Embossing Paper

\begin{tabular}{|c|c|c|c|c|c|c|}
\hline \multirow{2}{*}{ Configuration 2 } & \multicolumn{2}{|c|}{ 2-ply DECO Paper } & \multicolumn{2}{c|}{ 3-ply MICRO Paper } & \multicolumn{2}{c|}{ 5-ply Paper } \\
\cline { 2 - 7 } & CD & MD & CD & MD & CD & MD \\
\hline Tensile Index (Nm/g) & 1.6 & 5.0 & 4.5 & 9.2 & 3.5 & 6.8 \\
\hline Maximum Strain (\%) & 3.7 & 11.9 & 4.2 & 20.8 & 4.5 & 16.1 \\
\hline Young Modulus (MPa) & 2.8 & 3.0 & 21.6 & 9.3 & 11.8 & 6.6 \\
\hline
\end{tabular}

Figure 5 shows that the mechanical properties decreased and bulk increased due to the embossing process. In addition, a higher bulk increase value was observed for the 2ply mother reel than for the 3-ply mother reel. The tensile index decreased more in configuration 2 than in configuration 1 . The same trend was observed for the maximum strain and the Young's modulus. The deco embossing pattern used was more pronounced with deeper engraving details, as the authors showed in previous work with samples of the same 5-ply commercial toilet papers (Mendes et al. 2020). For this particular study, this deco embossing had a more negative impact on the mechanical properties than the micro embossing in both configurations. However, this impact was more noticeable in the 2-ply 
deco and micro embossing's. As expected, the embossing process negatively affected the mechanical properties of the tissue paper (Hollmark 1984).

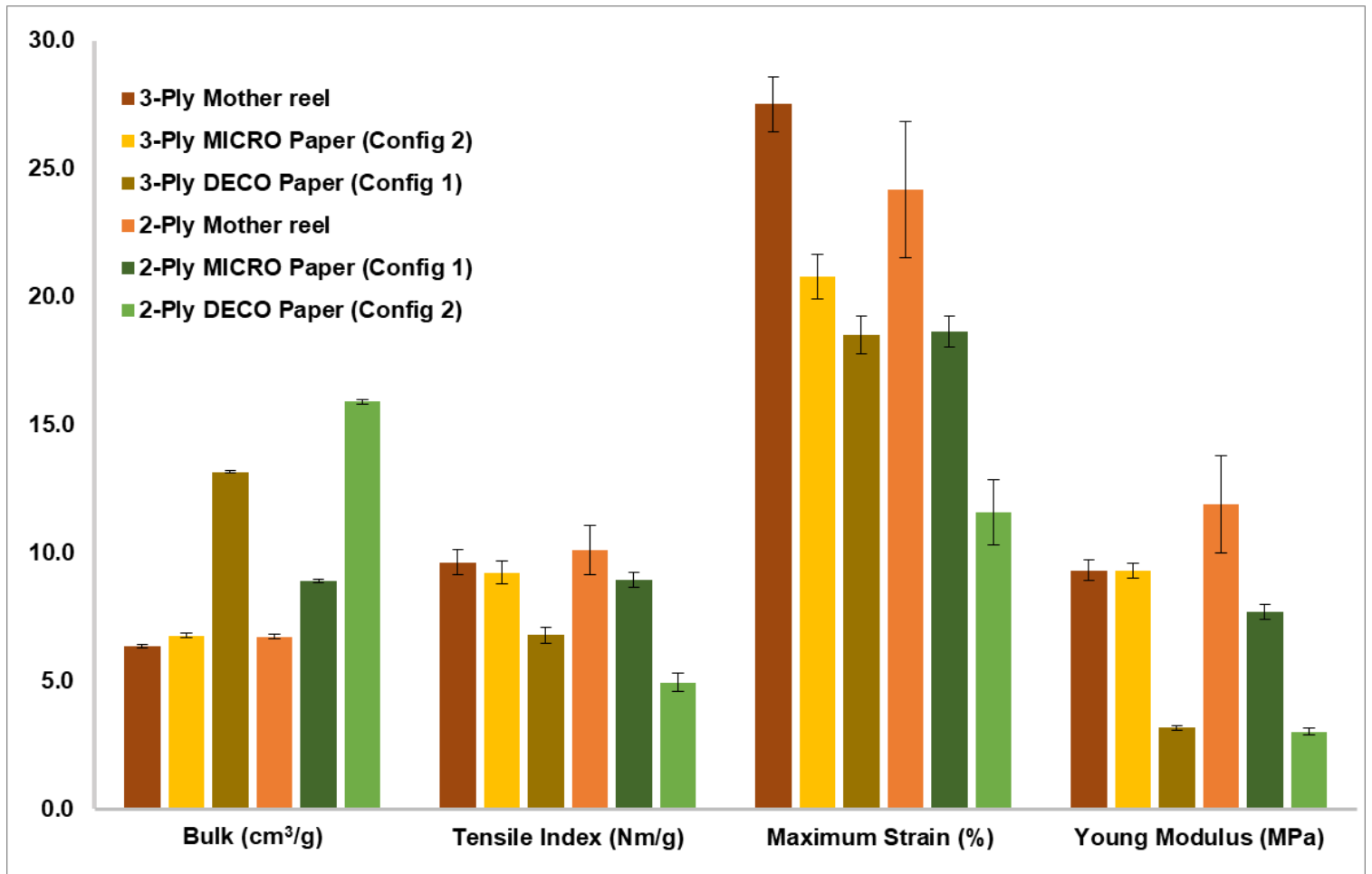

Fig. 5. Comparison of the mechanical properties (MD) of 2-ply and 3-ply mother reels with the corresponding deco and micro embossed papers

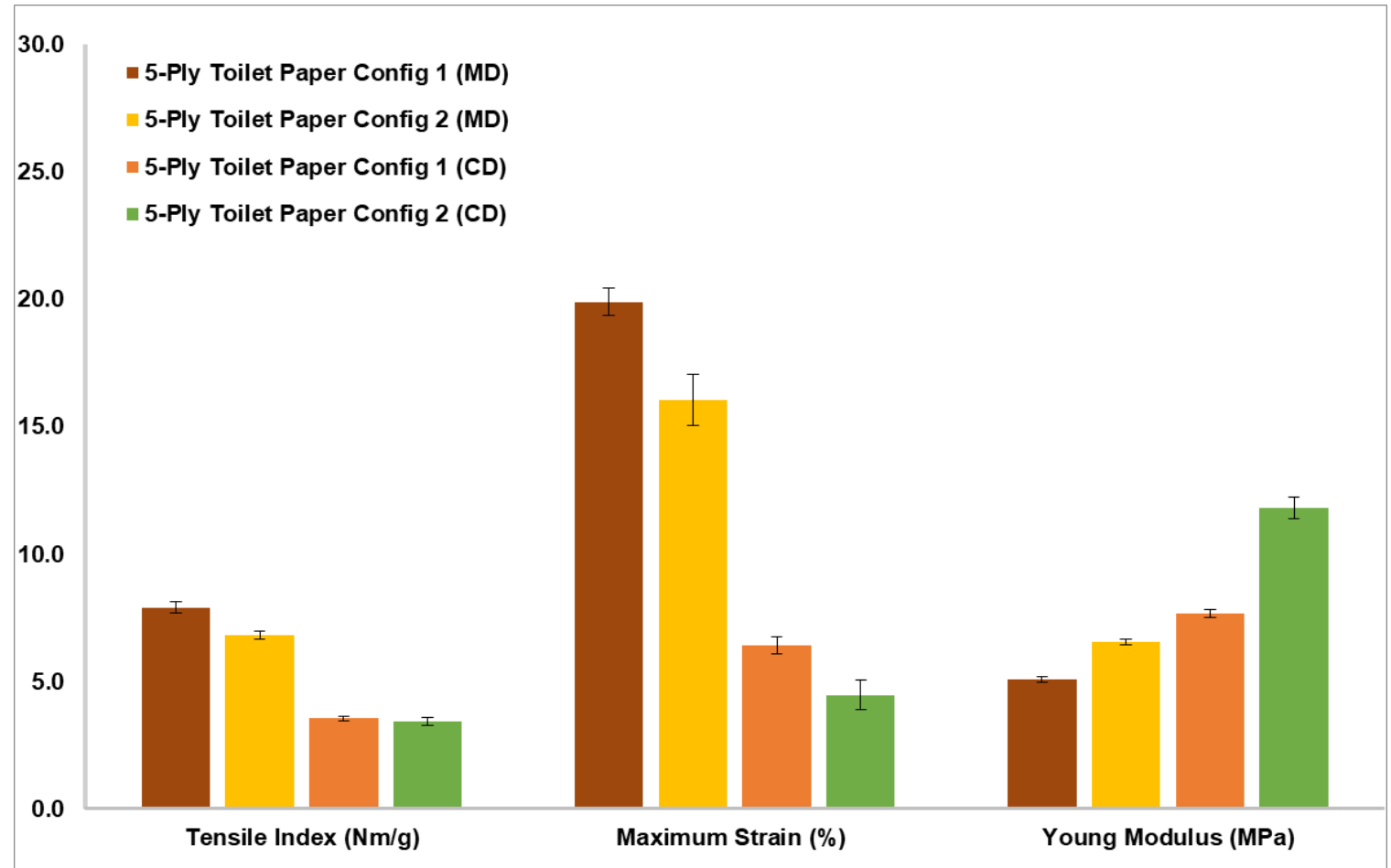

Fig. 6. Comparison of mechanical properties of the 5-ply toilet papers with configurations 1 and 2 
Figure 6 shows the comparison of the mechanical properties of the two studied configurations. Configuration 2 had lower tensile index and maximum strain values than configuration 1. However, configuration 2 had a higher Young's modulus value than configuration 1. This was true both for both MD and CD. Configuration 2 had lower mechanical property values because it had 1-ply less in the deco embossing, which further weakened the structure.

\section{CONCLUSIONS}

1. In this study, the morphological compositions of the finished toilet papers were characterized to identify the average values of the compositions of the base papers from which they were produced.

2. The thickness and bulk of the toilet papers increased due to the embossing process.

3. The water absorption times were similar without notable variation, so the embossing process had little impact on these values. As bulk increased $46 \%$ and $40 \%$ for configurations 1 and 2, respectively, water absorption capacity increased 2\% and 17\% for configurations 1 and 2, respectively. Therefore, the stacking sequence of the finished toilet paper sheets influenced water absorption capacity.

4. The embossing process changed the mechanical properties of the toilet papers. The tensile index, maximum strain, and Young's modulus decreased considerably due to the embossing process. Configuration 1 had minor losses in tensile index and maximum strain. However, configuration 1 had a higher loss in Young's modulus than configuration 2 . The negative impact on the mechanical properties was higher for deco embossing than for micro embossing in both configurations.

5. This study found that the stacking sequence of the sheets in the finished toilet papers influenced its final characteristics. For commercial purposes and to attend the final consumer preferences for toilet paper, configuration 1 was more suitable for mechanical strength, and configuration 2 was more suitable for absorption capacity.

\section{ACKNOWLEDGMENTS}

This work was carried out under Project InPaCTus - Innovative Products and Technologies from Eucalyptus (Project No. 21874) funded by Portugal 2020 through the European Regional Development Fund (ERDF) in the frame of COMPETE 2020 (No. 246/AXIS II/2017). In addition, the authors thank Fiber Materials and Environmental Technologies (FibEnTech-UBI) for their support (Grant No. UIDB/00195/2020).

\section{REFERENCES CITED}

Boudreau, J. (2013). New Methods for Evaluation of Tissue Creping and the Importance of Coating, Paper and Adhesion, Master's Dissertation, Karlstads Universitet, Karlstad, Sweden. 
Bracken, L. (2014). Potential for Utilization of Novel Modified Pulps in Tissue Paper Grades, Master's Dissertation, Miami University, Oxford, OH, USA.

Das, R. (2019). Experimental Studies on Creping and Its Influence on Mechanical Properties of Tissue Paper Products, Master's Dissertation, The University of British Columbia, Vancouver, Canada.

De Assis, T., Reisinger, L. W., Pal, L., Pawlak, J., Jameel, H., and Gonzalez, R. W. (2018). "Understand the effect of machine technology and cellulosic fibers on tissue properties - A review," BioResources 13(2), 4593-4629. DOI: 10.15376/biores.13.2.

Hollmark, H. (1984). "Mechanical properties of tissue," in: Handbook of Physical and Mechanical Testing of Paper and Paperboard, R. E. Mark (eds.), Marcel Dekker Inc., New York City, NY, USA, pp. 497-521.

Hubbe, M. A., Ayoub, A., Daystar, J. S., Venditti, R. A., and Pawlak, J. J. (2013). "Enhanced absorbent products incorporating cellulose and its derivatives: A review," BioResources 8(4), 6556-6629. DOI: 10.15376/biores.8.4.6556-6629

ISO 187 (1990). "Standard atmosphere for conditioning and testing and procedure for monitoring atmosphere and conditioning of samples," International Organization for Standardization, Geneva, Switzerland.

ISO 12625-3 (2014). “Tissue paper and tissue products - Part 3: Determination of thickness, bulking thickness and apparent bulk density and bulk," International Organization for Standardization, Geneva, Switzerland.

ISO 12625-4 (2005). "Tissue paper and tissue products - Part 4: Determination of tensile strength, stretch at break and tensile energy absorption," International Organization for Standardization, Geneva, Switzerland.

ISO 12625-6 (2005). "Tissue paper and tissue products - Part 6: Determination of grammage," International Organization for Standardization, Geneva, Switzerland.

ISO 12625-8 (2010). "Tissue paper and tissue products - Part 8: Water-absorption time and water-absorption capacity, basket-immersion test method," International Organization for Standardization, Geneva, Switzerland.

Kullander, J. (2012). Evaluation of Furnishes for Tissue Manufacturing, Master's Thesis, Karlstads Universitet, Karlstad, Sweden.

Mendes, A. de O., Vieira, J. C., Carta, A. M., Galli, E., Simões, R., Silva, M., Costa, A. P., and Fiadeiro, P. T. (2020). "Influence of tissue paper converting conditions on finished product softness." BioResources 15(3), 7178-7190. DOI: 10.15376/biores.15.3.7178-7190

Niskanen, K., Gullichsen, J., and Paulapuro, H. (1998). Papermaking Science and Technology. 16, Paper Physics, Fapet Oy, Helsinki, Finland.

Ramasubramanian, M. K., Sun, Z., and Chen, G. (2011). "A mechanics of materials model for the creping process," Journal of Manufacturing Science and Engineering 133(5), Article ID 051011. DOI: 10.1115/1.4004925

Spina, R., and Cavalcante, B. (2018). "Characterizing materials and processes used on paper tissue converting lines," Materials Today Communications 17, 427-437. DOI: 10.1016/j.mtcomm.2018.10.006

Tutuş, A., Çiçekler, M., and Çali, A. (2016). "Tissue papers in turkey and some physical and optical properties," Süleyman Demirel Universit Journal of Natural and Applied Sciences 20(1), 98-102. DOI: 10.19113/sdufbed.98003

Wang, Y., Zambrano F., Venditti R., Dasmohapatra S., De Assis T., Reisinger L., Pawlak J., and Gonzalez R. (2019). "Effect of pulp properties, drying technology, and 
sustainability on bath tissue performance and shelf price," BioResources 14(4), 94109428. DOI: 10.15376/biores.14.4.9410-9428

Vieira, J. C., De Oliveira Mendes, A., Carta, A. M., Galli, E., Torrão Fiadeiro, P., and Costa, A. P. (2020). "Impact of embossing on liquid absorption of toilet tissue papers," BioResources 15(2), 3888-3898. DOI: 10.15376/biores.15.2.3888-3898

Article submitted: June 4, 2020; Peer review completed: July 25, 2020; Revised version received and accepted: August 6, 2020; Published: August 12, 2020.

DOI: 10.15376/biores.15.4.7475-7486 